\title{
Screening of Prediabetics for Intervention Study in Coimbatore
}

\author{
K. Gomathi ${ }^{1 *}$ and M. Amirthaveni ${ }^{2}$ \\ 'Department of Home Science, Sri Sarada College for Women, Salem - 636016, \\ Tamil Nadu, India; goms.fsn@gmail.com \\ 2Department of Food Science and Nutrition, Avinashilingam University for Women, \\ Coimbatore - 641043, Tamil Nadu, India
}

\begin{abstract}
Prediabetes an asymptomatic intermediate state of hyperglycemia with blood glycemic parameters above normal but below the diabetes threshold with high probability of developing diabetes. Hence, main aim of the study was to screen the prediabetics using IDRS (Indian Diabetic Risk Score). Around 948 healthy volunteers (office administrators, employees, trainees and authorities) between the age of 25-60 years were selected from a Central Government funded center and from five private industries for screening the prediabetic subjects. From the 948 participants screened, $540(57 \%)$ were males and 408 (43\%) were females. About $35 \%$ male and $36.3 \%$ female subjects, were having an IDRS of $\geq 60$ and were categorized as subjects with high risk vulnerabilities. From the high risk vulnerabilities group, about 120 (35.6\%) subjects (64 male and 56 female) who had fasting blood glucose level ranging between $100-125 \mathrm{mg} / \mathrm{dl}$ were identified as prediabetics. The study revealed that the prediabetics can be screened in a simple and effective way for large populations.
\end{abstract}

Keywords: Diabetes, Hypoglycemia, Indian Diabetic Risk Score, Prediabetes

\section{Introduction}

Currently, prediabetes is a term covering two possible heterogeneous condition by the presence of Impaired Fasting Glucose (IFG) and/or Impaired Glucose Tolerance (IGT) that has not yet reached the thresholds for diagnosable Type II diabetes. Prediabetes raises the risk of Type II diabetes by 3 - to 10 -fold ${ }^{1}$. The prevalence of prediabetes is estimated to be over 330 million people worldwide and expected to raise to at least 470 million in $2030^{2}$. Worldwide, the number of people with IGT is estimated to be 280 million; by 2030 , it is expected to be 398 million. Continuous rather than dichotomous risk scores are more useful for predicting the risk of developing diabetes. Hence the present study was carried out to screen the prediabetics for further food based intervention.

\section{Materials and Methods}

\subsection{Selection of Area for Screening the Prediabetics}

Before developing Type II diabetes, majority have "prediabetes" in which the blood sugar levels are higher without symptoms. Hence healthy volunteers (office administrators, employees, trainees and authorities) between the age of 25-60 years were selected from a Central Government funded center and from five private industries for screening the prediabetic subjects.

The study was registered in the Clinical Trial Registry of India (CTRI), Indian Council of Medical Research (ICMR). CTRI registration number is CTRI/2013/06/003759. The methodology of the present study was presented before the Institutional Human 
Ethical Committee (IHEC) of Avinashilingam University and the approval number AUW/IHEC-2013 AP-01 was obtained to conduct the clinical trial.

\subsection{Screening using Indian Diabetic Risk Score (IDRS)}

The study design, duration of the study and expected outcome of the study was explained and oriented to all the 948 participants by a formal meeting in their work premises itself. This was arranged with the support of the authorities of concerned industries and informed written consent was obtained from all the participants before the start of the study.

IDRS is a simple, very low-cost screening tool developed by Mohan et al. (2005) ${ }^{3}$ having multiple potential applications in clinical and epidemiological settings in India and was used to identify the prediabetics in the study. The screening of prediabetics was done using the Indian Diabetic Risk Score (Table 1).

Table 1. Indian diabetes risk score*

\begin{tabular}{|l|c|}
\hline \multicolumn{2}{|c|}{ Criteria Assessed } \\
\hline Age (Yrs) & Std. Points \\
\hline$<35$ & 20 \\
\hline $35-49$ & 30 \\
\hline$\geq 50$ & \\
\hline Waist circumference (cm) & 0 \\
\hline$<80$ (female), $<90$ (male) & 10 \\
\hline $80-89$ (female), 90 -99 (male) & 20 \\
\hline$\geq 90$ (female), $\geq 100$ (male) & 0 \\
\hline Physical activity & 10 \\
\hline $\begin{array}{l}\text { Vigorous regular exercise or manual } \\
\text { work at home/work }\end{array}$ & 20 \\
\hline $\begin{array}{l}\text { Moderate regular exercise or physical } \\
\text { activity at home/work }\end{array}$ & 30 \\
\hline $\begin{array}{l}\text { Mild regular exercise or physical } \\
\text { activity at home/work }\end{array}$ & \\
\hline $\begin{array}{l}\text { No exercise and sedentary activities at } \\
\text { home/work }\end{array}$ & \\
\hline Family history of diabetes & \\
\hline No diabetes in parents & \\
\hline One parent diabetic & \\
\hline Both parents diabetic & \\
\hline
\end{tabular}

*Mohan et al., (2005) ${ }^{3}$
Subjects with an IDRS risk points $<30$ were categorized as low risk, between 30 and 50 points as medium risk and those with $\geq 60$ points are high risk for developing diabetes.

\section{Results and Discussion}

\subsection{Age and Sex Wise Distribution of the Selected Participants}

Figure 1 reveals the age and gender wise distribution of the 948 selected population screened using IDRS.

Of the 948 participants screened, $540(57 \%)$ were males and 408 (43\%) were females.

A study by Sosale et al., $(2014)^{4}$ confirms that the newly diagnosed diabetics were from a younger age between 31-40 years (35\%) and almost equal (40\%) population was from the age group of 41-50 years. Younger age of onset implies that the most productive years of life is utilized and has a greater chance of rising complications. Both environmental and genetic factors might explain the younger onset of age along with high prevalence of diabetes in the Indian population. Hence the participants aged 25 years onwards were screened to identify the prediabetes.

From the 540 male subjects, most (35.4\%) of the selected subjects were in the age group between $31-40$ years followed by $30.6 \%$ in $41-50$ years of age. Only a minimum of $2 \%$ of these selected male subjects were more than 60 years of age. Among the 408 female subjects screened, a higher percentage (47.1) were in the age between $31-40$ years and $31.1 \%$ were less than 30 years of age. Around $17.6 \%$ and $4.2 \%$ were in the age group of 41-50 years and 51-60 years respectively.

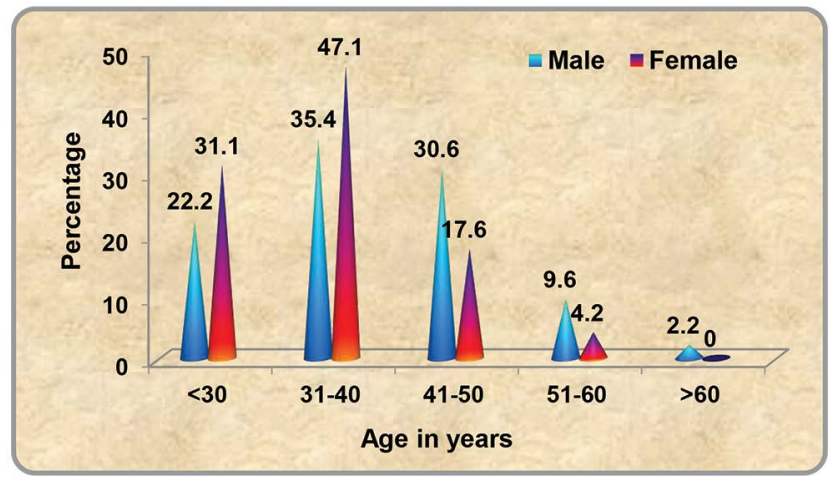

Figure 1. Age and sex wise distribution of the participants. 


\subsection{BMI Classification of Participants}

Table 2 portraits the classification of screened subjects according to their BMI.

According to American Diabetes Association (2014) "lower BMI cut off points, specifically $24 \mathrm{~kg} / \mathrm{m}^{2}$ in South Asians and $25 \mathrm{~kg} / \mathrm{m}^{2}$ in Chinese, denote increased diabetes risk in some racial and ethnic groups".

It is noticed from the above Table 2, among the 540 male subjects, $56.3 \%$ of them were considered to be normal having BMI ranging from 18.5-24.99. Very few (9.6\%) of male subjects were underweight. Almost 28.7\% of the subjects were in preobese category with the BMI of $\geq 25$ and are considered to be overweight. $3.5 \%$ were under mild obese class I category, $1.1 \%$ in moderate obese class I and only $0.2 \%$ each in moderate obese class II and obese class III categories.

Among the 549 female subjects, $41.2 \%$ were in normal BMI range between 18.5-24.99. Only $6.9 \%$ of the females were underweight (whose BMI was <18.49). Among these subjects, $36.5 \%$ were under the pre obese category, $10 \%$ falls under mild obese class I category, $2.9 \%$ were under moderate obese class I category, $1.5 \%$ under mild obese class II category and $1 \%$ was under moderate obese class II category.

\subsection{Waist Circumference of the Selected Participants}

Classification of screened subjects according to waist circumference is presented in Table 3.

Among the South Asians, in both men and women, the waist circumference cut-point was consistently lower than in whites which is $102 \mathrm{~cm}$ for men or $88 \mathrm{~cm}$ for women. Based on findings of Bodicoat et al., (2014) $)^{8}$ it was recommended a waist circumference threshold of 90 $\mathrm{cm}$ for men and $77 \mathrm{~cm}$ for women in South Asians.

With regard to waist circumference, a higher percentage (63.5) of the male subjects were in normal range with $<90 \mathrm{~cm}$ whereas $37.7 \%$ of female subjects were having their waist circumference of $80-89 \mathrm{~cm}$ and were categorized under risk category. About $27.5 \%$ of the female subjects were having $\geq 90 \mathrm{~cm}$ as their waist circumference in turn increases the metabolic rate.

\subsection{Physical Activity Status of the Selected Participants}

Distribution of screened subjects according to their physical activity status is given in Table 4. ICMR-INDIAB-5 study by Anjana et al., (2014) $)^{9}$ revealed that "among

Table 2. BMI classification of the participants

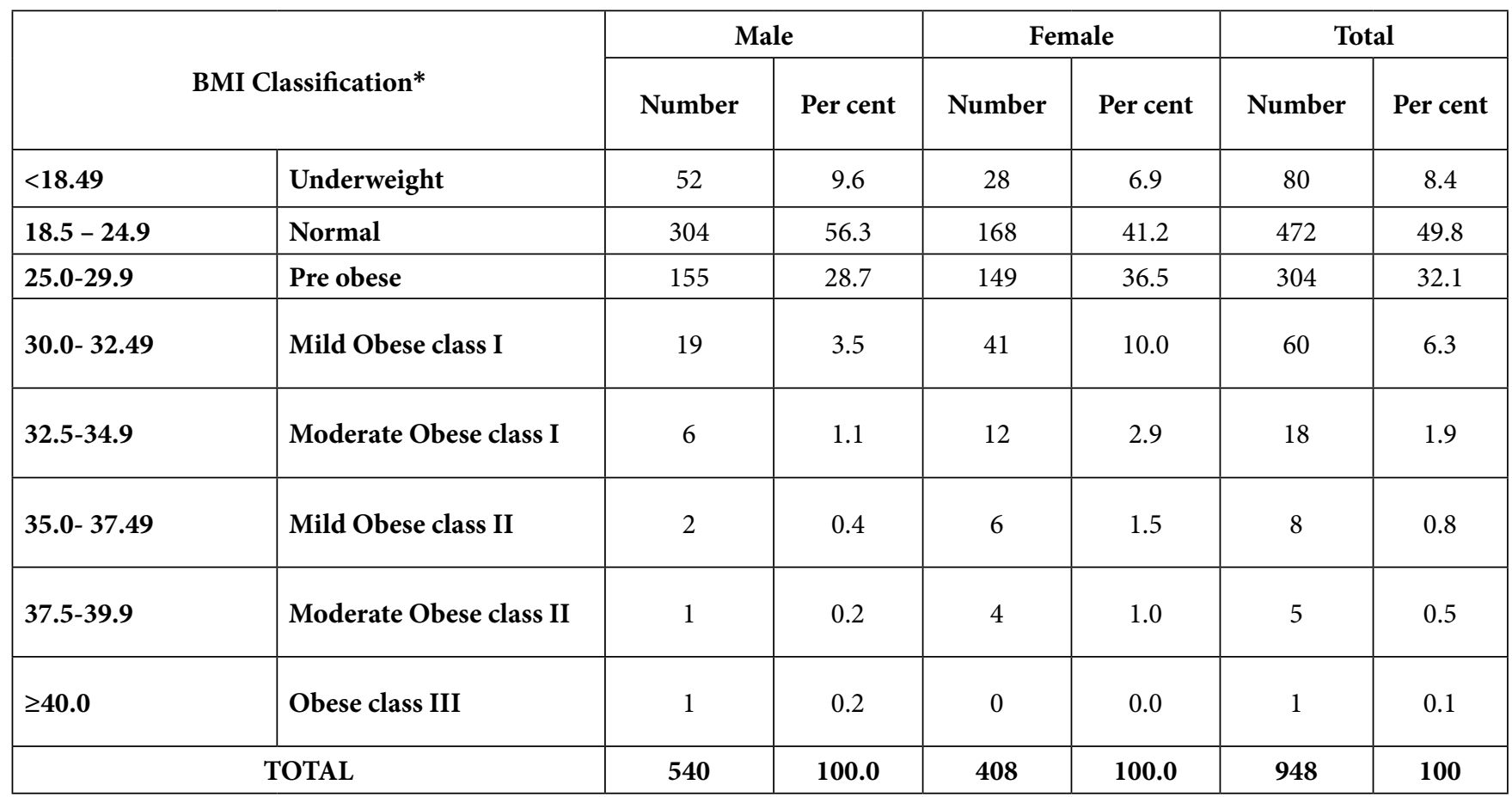

*WHO $(2004)^{5}$ 
Table 3. Waist circumference of the selected participants

\begin{tabular}{|c|c|c|c|c|c|}
\hline \multirow{2}{*}{ Waist circumference* $(\mathbf{c m})$} & \multicolumn{2}{|c|}{ Male } & \multicolumn{2}{|c|}{ Female } \\
\cline { 2 - 6 } & Number & Per cent & Paist circumference* $(\mathbf{c m})$ & Number & Per cent \\
\cline { 2 - 6 } & 343 & 63.5 & $<80$ & 142 & 34.8 \\
\hline $\mathbf{9 0 - 9 9}$ & 138 & 25.6 & $80-89$ & 154 & 37.7 \\
\hline $\mathbf{9 0 0}$ & 59 & 10.9 & $\geq 90$ & 112 & 27.5 \\
\hline Total & 173 & 100 & Total & 100 \\
\hline
\end{tabular}

*WHO $(2008)^{7}$

Table 4. Physical activity status of the selected participants

\begin{tabular}{|c|c|c|c|c|c|c|}
\hline \multirow{2}{*}{ Physical activity } & \multicolumn{2}{|c|}{ Male } & \multicolumn{2}{|c|}{ Female } & \multicolumn{2}{|c|}{ Total } \\
\hline & Number & Percent & Number & Percent & Number & Percent \\
\hline Vigorous exercise or manual work at home/work site & 0 & 0.0 & 1 & 0.2 & 1 & 0.1 \\
\hline Moderate exercise or physical activity at home/work site & 15 & 2.8 & 6 & 1.5 & 21 & 2.2 \\
\hline Mild exercise or physical activity at home/work site & 86 & 15.9 & 37 & 9.1 & 123 & 13.0 \\
\hline No exercise and sedentary activities at home/worksite & 439 & 81.3 & 364 & 89.2 & 803 & 84.7 \\
\hline Total & 540 & 100 & 408 & 100.0 & 948 & 100.0 \\
\hline
\end{tabular}

14227 individuals studied, $54.4 \%(\mathrm{n}=7737)$ were inactive while $31.9 \%(\mathrm{n}=4537)$ were active and $13.7 \%(\mathrm{n}=1953)$ were highly active. The region-wise prevalence of physical inactivity was as follows: Chandigarh-66.8\%, Tamil Nadu60.0\%, Maharashtra- 55.2\% and Jharkhand-34.9\%. When extrapolated to the whole country, the estimated number of inactive individuals in India would be 392 million". The present study findings may also bear same results that higher percent of both male and female (81.3 and 89.2\%) subjects were not doing exercise.

About $15.9 \%$ of male and $9.1 \%$ of female belong to mild physical activity category where as 2.8 and $1.5 \%$ of the male and female subjects respectively were doing moderate exercise or strenuous work category.

It was heartening to know that about $81.3 \%$ of male and $89.2 \%$ of female subjects were not excercising and they belonged to sedentary activity which was one of the important risk factor for developing diabetes.

\subsection{Family History of the Selected Participants}

Table 5 shows the screened subjects according to their family history of diabetes

With regard to the family history, 126 (23.3\%) males and $122(29.9 \%)$ of females were having positive history of diabetes in one of the parent and 3.9\% male and $4.2 \%$ female respectively in both parents. Almost similar finding was revealed by Kumar et al., $(2014)^{10}$ who reported 32\% of the screened subjects with single parental history and $6 \%$ in both parents.

\subsection{Classification of Screened Subjects as per IDRS}

Details of the screened participants (N-948) for the clinical trial are presented in Table 6.

About 35\% male and $36.3 \%$ female subject, were having an IDRS risk score of $\geq 60$ and were categorized as subjects with high risk vulnerabilities. Higher percentages (62.6\%) of the subjects were in the medium risk and only $1.9 \%$ of subjects were in low risk catogery.

All the subjects with high risk vulnerabilities were further tested for their Fasting Blood Glucose (FBG) level to confirm prediabetic status. The fasting blood glucose was analysed from capillary blood after 12 hours fasting 
Table 5. Family history of diabetes

\begin{tabular}{|l|c|c|c|c|c|c|}
\hline \multirow{2}{*}{ Family history } & \multicolumn{2}{c|}{ Male } & \multicolumn{2}{c|}{ Female } & \multicolumn{2}{c|}{ Total } \\
\cline { 2 - 7 } & Number & Per cent & Number & Per cent & Number & Per cent \\
\hline No genetic history & 393 & 72.8 & 269 & 65.9 & 662 & 24.8 \\
\hline Single parent & 126 & 23.3 & 122 & 29.9 & 248 & 38 \\
\hline Both parents & 21 & 3.9 & 17 & 4.2 & 4.0 \\
\hline Total & 540 & 100 & 408 & 100 & 948 & 100.0 \\
\hline
\end{tabular}

Table 6. Classification of screened subjects as per IDRS

\begin{tabular}{|c|c|c|c|c|c|c|c|c|}
\hline \multirow[t]{2}{*}{ Sex } & \multicolumn{2}{|c|}{ Low risk vulnerabilities } & \multicolumn{2}{|c|}{$\begin{array}{c}\text { Medium risk } \\
\text { vulnerabilities }\end{array}$} & \multicolumn{2}{|c|}{$\begin{array}{c}\text { High risk } \\
\text { vulnerabilities }\end{array}$} & \multicolumn{2}{|c|}{ Total } \\
\hline & No & $\%$ & No & $\%$ & No & $\%$ & No & $\%$ \\
\hline Male & 14 & 2.6 & 337 & 62.4 & 189 & 35 & 540 & 57 \\
\hline Female & 4 & 1 & 256 & 62.7 & 148 & 36.3 & 408 & 43 \\
\hline Total & 18 & 1.9 & 593 & 62.6 & 337 & 35.5 & 948 & 100 \\
\hline
\end{tabular}

with Accucheck active glucometer (Roche Diagnostics, Germany) and the blood glucose values were recorded. Breakfast was provided for all the participants involved in FBG screening.

\subsection{Distribution of Screened Subjects as per Blood Glucose Level}

Table 7 reveals the distribution of screened subjects as per blood glucose level.

From the high risk vulnerabilities group, around $60.8 \%$ of the subjects were having desirable blood glucose level of $<100 \mathrm{mg} / \mathrm{dl}$. About 120 (35.6\%) subjects (64 male and 56 female) had fasting blood glucose level ranging between $100-125 \mathrm{mg} / \mathrm{dl}$ and identified as prediabetics as per American Diabetes Association (2013) ${ }^{6}$. Around 12 subjects who were not diagnosed before as diabetics were also identified during the screening and advised to monitor

Table 7. Distribution of screened subjects as per blood glucose level

\begin{tabular}{|c|c|c|c|c|c|c|c|}
\hline \multirow{2}{*}{ Sex } & \multicolumn{2}{|c|}{$\begin{array}{c}\text { Normal } \\
\text { subjects }\end{array}$} & \multicolumn{2}{l|}{ Prediabetics } & \multicolumn{2}{l|}{ Diabetics } & Total \\
\cline { 2 - 8 } & No & $\%$ & No & $\%$ & No & $\%$ & No \\
\hline Male & 113 & 59.7 & 64 & 33.8 & 12 & 6.34 & 189 \\
\hline Female & 92 & 62.2 & 56 & 37.8 & 0 & 0 & 148 \\
\hline Total & 205 & 60.8 & 120 & 35.6 & 12 & 3.6 & 337 \\
\hline
\end{tabular}

their blood glucose level further with a diabetologist and confirm their status. Among the 120 prediabetics identified, based on the willingness and ready to give written consent, 90 prediabetics (male 53 and female 37) were selected from various venue to participate in the clinical trial.

\section{Conclusion}

The study revealed that prediabetics can be screened in a simple and effective way for large populations. Specially designed interventions along with changes in modifiable risk factors will reduce the incidence of prediabetes.

\section{Reference}

1. Centers for Disease Control and Prevention. National Diabetes Fact Sheet: Diagnosed and undiagnosed diabetes in the United States, all ages, 2010; 2011. Available from: http:// www.cdc.gov/diabetes/pubs/estimates11.htm\#10

2. International Diabetes Federation. Diabetes atlas. 6th ed; 2013. Available from: www.diabetesatlas.org

3. Mohan V, Deepa R, Deepa M, Somannavar S, Datta M. A simplified Indian diabetes risk score for screening for undiagnosed diabetic subjects. Journal of Associations of Physicians of India. 2005; 53(7):59-63.

4. Sosale A, Kumar KMP, Sadikot SM, Nigam A, Bajaj S, Zargar AH, Singh SK. Chronic complications in newly diagnosed patients with Type 2 diabetes mellitus in India. Indian Journal of Endocrinology and Metabolis. 2014; 18(3): 355-60. https://doi.org/10.4103/2230-8210.131184 PMid:24944931 PMCid:PMC4056135 
5. WHO. The global burden of disease: 2004 update. Geneva: World Health Organization, 2008; 2004.

6. American Diabetes Association; 2013. Available from: http:// www.diabetes.org/food-and-fitness/food/what-can-i-eat

7. WHO. Waist Circumference and Waist-Hip Ratio Report of a WHO Expert Consultation; Geneva. 2008 Dec 8-11. p. 27-8.

8. Bodicoat DH, Laura J, Gray, Joseph, Henson, Webb D, Guru A, Misra A, Gupta R, Vikram N, Sattar N, Davies MJ, Khunti K. Body mass index and waist circumference cut-points in multi-ethnic populations from the UK and India: The addition-Leicester, Jaipur heart watch and New Delhi cross-sectional studies. Plos One. 2014; 9(3): 90813-15. https://doi.org/10.1371/journal.pone.0090813 PMid:24599391 PMCid:PMC3944886
9. Anjana RM, Pradeepa R, Das AK, Deepa M, Bhansali A, Joshi SR, Joshi PP, Dhandhania VK, Rao PV, Sudha V, Subashini R, Unnikrishnan R, Madhu SV, Kaur T, Mohan V, Shukla DK. For the ICMR- INDIAB collaborative study group, physical activity and inactivity patterns in India-results from the ICMR-INDIAB study (Phase-1) [ICMR-INDIAB-5]. International Journal of Behavioral Nutrition and Physical Activity. 2014; 11: 26. https://doi.org/10.1186/1479-586811-26 PMid:24571915 PMCid:PMC3974063

10. Kumar GS, Neeraj K, Khare S. A study of diabetes prevalence and its risk factors in the medical college faculty of Bhopal, Madhya Pradesh. Austin Journal of Endocrinology Diabetes. 2014; 1(2): 1-3. 